\title{
Type II hyperprolinaemia in a pedigree of Irish travellers (nomads)
}

\author{
M P FLYNN, M C MARTIN,${ }^{*}$ P T MOORE, ${ }^{*} \mathrm{~J}$ A STAFFORD,${ }^{*} \mathrm{G}$ A FLEMING,$\dagger$ AND J M PHANG $\dagger$ \\ Midland Health Board, Mullingar and *St James's Hospital, Dublin, Ireland and †Metabolism Branch, \\ National Cancer Institute, National Institutes of Health, Bethesda, Maryland, USA
}

SUMMARY We describe a study of 312 subjects in 71 families near related to a proband with type II hyperprolinaemia. The subjects were Irish travellers (nomads) among whom consanguineous marriage and high fertility are common. Thirteen additional cases of type II hyperprolinaemia were discovered; all were offspring of consanguineous unions. A further 50 subjects were found to have mild hyperprolinaemia. We found a strong association between type II hyperprolinaemia and seizures during childhood but no significant association with mental handicap. Most adults with type II hyperprolinaemia enjoyed normal health and there was no evidence that maternal hyperprolinaemia compromised fetal development. The documented association between type II hyperprolinaemia and seizures may be related to the neuromodulatory or reducing-oxidising effects of proline and pyrroline-5-carboxylate, respectively, that has been shown in vitro. Alternatively, another genetic defect closely linked to the type II hyperprolinaemia allele could be the explanation.

Hyperprolinaemia is a disorder of metabolism characterised biochemically by a raised concentration of plasma proline and by aminoaciduria consisting of proline, hydroxyproline, and glycine. The urinary excretion of hydroxyproline and glycine is due to a saturation by proline of an active transport system in the renal tubule, which shares affinity for proline, hydroxyproline, and glycine. ${ }^{12}$ Proline and hydroxyproline are non-essential amino acids. Beyond early infancy there is virtually no proline in normal urine.

Twenty families with the rare biochemical disorder, hyperprolinaemia, are known to the authors from the literature. ${ }^{13}$ On the basis of the findings in these families and pedigrees the hyperprolinaemia trait can be divided into two forms: type I hyperprolinaemia, caused by defective proline oxidase activity and type II hyperprolinaemia, caused by deficient $\triangle$-pyrroline-5-carboxylic acid dehydrogenase (P5CD) activity. Both forms are the result of mutant alleles at different genetic loci and are inherited in autosomal recessive fashion. Consanguinity of the parents was noted in several of the 20 previously reported families.

\section{Metabolism of L-proline and clinical phenotypes}

L-proline is first oxidised by proline oxidase to $\triangle$-pyrroline-5-carboxylic acid (P5C). P5C is in equilibrium spontaneously with glutamic acid $\gamma$ semialdehyde, which is oxidised by P5CD to glutamic acid. Glutamic acid semialdehyde can also be transaminated to form ornithine. Proline oxidase is mitochondrial and found in relatively few tissues while $\mathrm{P} 5 \mathrm{CD}$ is cytosolic and ubiquitous. ${ }^{4}$ The pathway of mammalian proline metabolism is shown in fig 1.

Based on a number of reports the normal plasma proline range may lie between 80 and $350 \mu \mathrm{mol} / 1 .{ }^{15}$ The concentration in type II hyperprolinaemia, with few exceptions, is in excess of $1300 \mu \mathrm{mol} / \mathrm{l}$ and may be as high as $3000 \mu \mathrm{mol} / \mathrm{l}$, whereas, in type I the concentration rarely exceeds $1700 \mu \mathrm{mol} / \mathrm{l}$. As the block in type II hyperprolinaemia is at the second stage of catabolism, people with this condition have appreciably raised concentrations of plasma P5C and excrete $\mathrm{P} 5 \mathrm{C}$ in their urine. These latter findings distinguish type II hyperprolinaemia from type I.

Proline has been found to have neurotransmitter 
1700 Flynn, Martin, Moore, Stafford, Fleming, and Phang

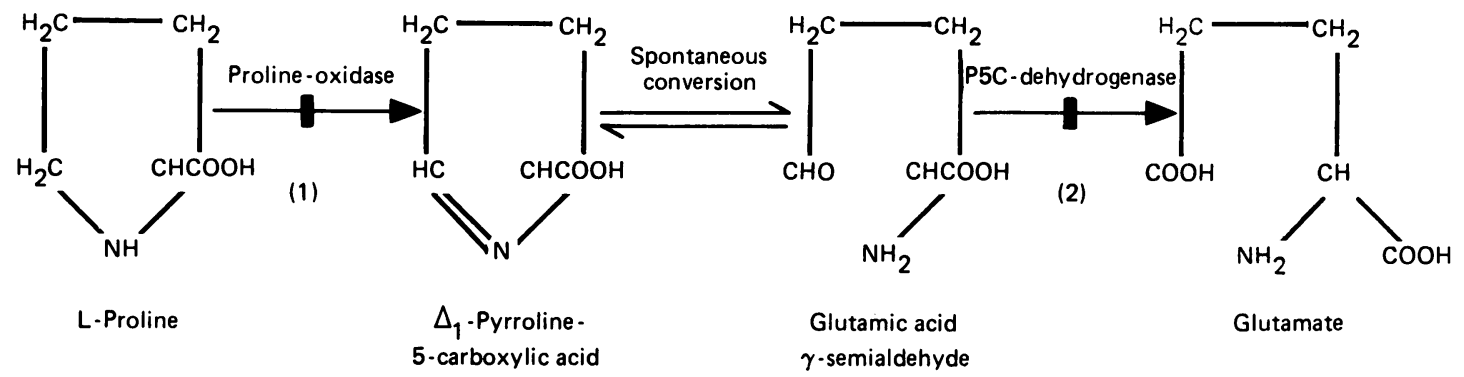

Fig 1 Pathway of mammalian proline metabolism with two known human metabolic blocks indicated: (1) in type I hyperprolinaemia, (2) in type II hyperprolinaemia.

properties to which $\mathrm{P} 5 \mathrm{C}$ may contribute but the effect of high plasma proline or high plasma P5C concentrations on brain function is unclear. ${ }^{16}$ In the earliest reports of type I and type II hyperprolinaemia an association of the conditions with diverse clinical abnormalities was reported, namely, hereditary nephropathy, deafness, mental handicap, and seizures. ${ }^{57}$ In subsequent reports, families were described in which hyperprolinaemia occurred in the absence of clinical disease and many believe that the hyperprolinaemias are benign conditions. ${ }^{8-12}$ However, a cause and effect relationship between type II hyperprolinaemia and convulsive seizures was not completely ruled out.

\section{The investigation}

The investigation reported here commenced with the family of the proband, who had hyperprolinaemia, iminoglycinuria, and mental handicap and was subject to seizures. Part of the family pedigree is shown in fig 2; the proband is IV.22. There was a high incidence of seizures among his siblings, four of whom were mentally handicapped. Subsequently, the investigation was extended to many other families with the same paternal ancestry. All were 'travellers' (itinerants, tinkers, gypsies) among whom teenage marriage of cousins, particularly first cousins, and high fertility are common. ${ }^{13}$ The word 'gypsies' is used in the descriptive sense only. Members of the group are not of Romany origin but are racially Irish. ${ }^{14}$ Most of those over 20 years of age are illiterate. In recent years many have settled in houses. While not of Romany origin their characteristics and practices resemble, in many respects, those described by Thomas for Romany gypsies of the United States among whom marriage between second cousins is considered ideal. ${ }^{15}$ Travellers are very suspicious of outsiders.
However, the first named author is generally trusted by them having done voluntary social work with them for many years. Thomas got exposure to their culture by caring for them and gaining the title 'Gypsy doctor'.

Samples of urine and blood were collected in the family house or caravan, apart from a few collected during clinic or hospital attendance. Cooperation, although sometimes slowly attained, was excellent there being only two refusals at initial approach. However, requests for repeat specimens were sometimes unsuccessful. Furthermore, the scattered geographic location and mobility, even to the United Kingdom, were limiting factors in obtaining specimens for follow up tests. During the repeated home visits the family medical history was taken, with detailed questioning about possible convulsive episodes. Confirmation of a history of seizures given by the subjects or their parents was obtained from family doctors and hospital records. The term seizure embraces febrile convulsions, isolated single seizures, recurrent petit mal and grand mal epileptic type convulsions. Despite the hardship and rigours of their way of life travellers have no special health problems other than an increased liability to physical injury. ${ }^{13} 14$

Assessment of IQ (by the revised Wechsler intelligence scale for children) was performed on 19 schoolgoing children of the pedigree: five with type II hyperprolinaemia, five with mild hyperprolinaemia, and nine with normal plasma proline. One of the children with type II hyperprolinaemia had an IQ of 55 and another an IQ of 70. One child with mild hyperprolinaemia had an IQ of 75 , and the remainder had an IQ of 80 or higher. Mental handicap is defined as having an IQ $<70$ on the Wechsler scale. Two preschool children with type II disease, who showed normal development, were not formally tested. Other members of the pedigree 


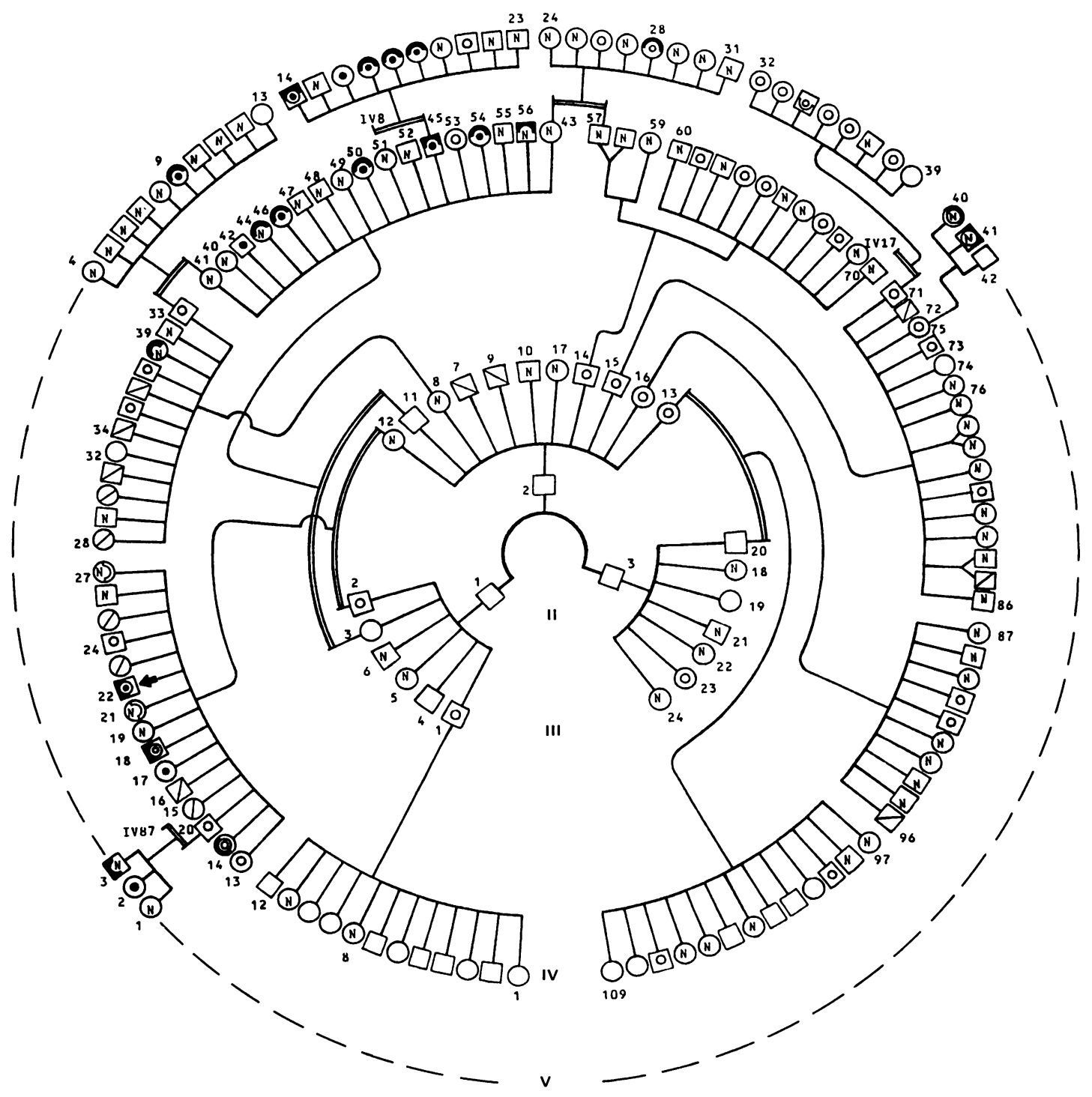

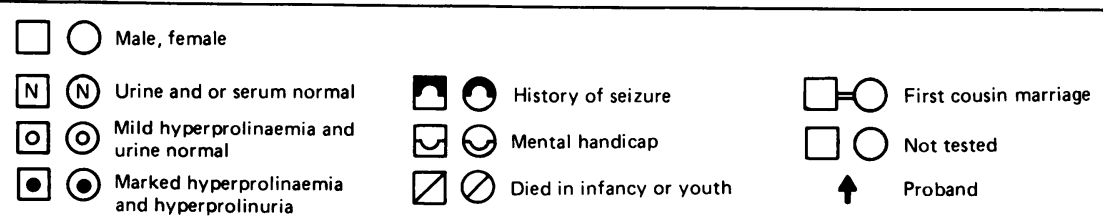

Fig 2 Type II hyperprolinaemia in a pedigree of Irish travellers. 


\section{Flynn, Martin, Moore, Stafford, Fleming, and Phang}

with mental handicap were known from previous clinical assessments.

\section{Methods}

Preliminary screening involved the qualitative testing of urine from the family of the proband and some close relatives for amino acids by two dimensional paper chromatography. Those showing prolinuria, their immediate family, and some members of the extended family, had blood samples taken in plain tubes, and their serum or plasma proline concentrations were determined on a Locarte amino acid analyser. A total of 312 subjects were screened: urine was collected from 280 and blood from 147. In 32 cases no urine was collected but a blood sample was. Many repeat samples were taken. Concentrations of urinary amino acids were determined on the Locarte analyser using random samples. The reference values for serum proline used for adults were those given by Dickenson et al: mean 184 (range 102-336) $\mu \mathrm{mol} /{ }^{16}{ }^{16}$ The reference values of Clayton et al were used for children: mean 185 (range 89-281) $\mu \mathrm{mol} / \mathrm{l}^{17}$

The method described by Strecker was used in testing for orthoaminobenzaldehyde reactive substances in the urine. ${ }^{18}$

Plasma P5C concentration and leucocyte P5CD activity were quantitated on five subjects with prolinuria and hyperprolinaemia and 32 other pedigree members and two normal controls. For plasma P5C concentrations, $10 \mathrm{ml}$ of heparinised whole blood was immediately chilled in an ice slurry. Plasma obtained by centrifugation was deproteinised with $50 \%$ trichloroacetic acid to a final concentration of $10 \%$ and stored at $-20^{\circ} \mathrm{C}$. Plasma P5C concentrations were determined by a published method. ${ }^{19}$ For P5CD measurements, leucocytes were obtained by dextran sedimentation from $10 \mathrm{ml}$ of heparinised whole blood. The cells were washed twice in phosphate buffer $(0.1 \mathrm{M}, \mathrm{pH} 8.0)$ and stored at $-20^{\circ} \mathrm{C}$. The samples were carried to Bethesda, Maryland in carbon dioxide snow. P5CD activities were measured using a previously described specific radioisotopic method, ${ }^{20}$ and proteins in the extracts were estimated by the method of Lowry et al. ${ }^{21}$

\section{Results}

In addition to the proband, who was discovered to have hyperprolinaemia in 1972, at 10 years of age, prolinuria was found in a further 13 subjects (three males, 10 females) from five families. Serum proline concentration was above $2000 \mu \mathrm{mol} / \mathrm{l}$ in 10 and slightly under that level in two (table 1). It was not convenient to take blood from one child (V.19) but quantitative urinalysis showed iminoglycinuria.

Table 1 Personal details and amino acid profiles of pedigree members with type II hyperprolinaemia

\begin{tabular}{|c|c|c|c|c|c|c|c|c|c|c|}
\hline \multirow[t]{2}{*}{$\begin{array}{l}\text { Pedigree } \\
\text { No } \\
\text { (fig 2) }\end{array}$} & \multirow[t]{2}{*}{ Sex } & \multirow[t]{2}{*}{$\begin{array}{l}\text { Age } \\
\text { (years) }\end{array}$} & \multirow[t]{2}{*}{$\begin{array}{l}\text { Qualitative } \\
\text { urinary } \\
\text { proline }\end{array}$} & \multicolumn{2}{|c|}{$\begin{array}{l}\text { Quantitative urinary } \\
\text { amino acids } \\
(\mu \mathrm{mol} / \mathrm{l})\end{array}$} & \multicolumn{2}{|l|}{$\begin{array}{l}\text { Serum } \\
\text { proline } \\
(\mu \mathrm{mol} / \mathrm{l})\end{array}$} & \multirow[t]{2}{*}{$\begin{array}{l}\text { Plasma } \\
\text { P5C } \\
(\mu \mathrm{mol} / \mathrm{l})\end{array}$} & \multirow[t]{2}{*}{$\begin{array}{l}\text { Suffered } \\
\text { from } \\
\text { seizures }\end{array}$} & \multirow[t]{2}{*}{$\begin{array}{l}\text { Mental } \\
\text { handicap }\end{array}$} \\
\hline & & & & Proline & $\begin{array}{l}\text { Hydroxy- Glycine } \\
\text { proline }\end{array}$ & Fasting & $\begin{array}{l}\text { Non- } \\
\text { fasting }\end{array}$ & & & \\
\hline
\end{tabular}

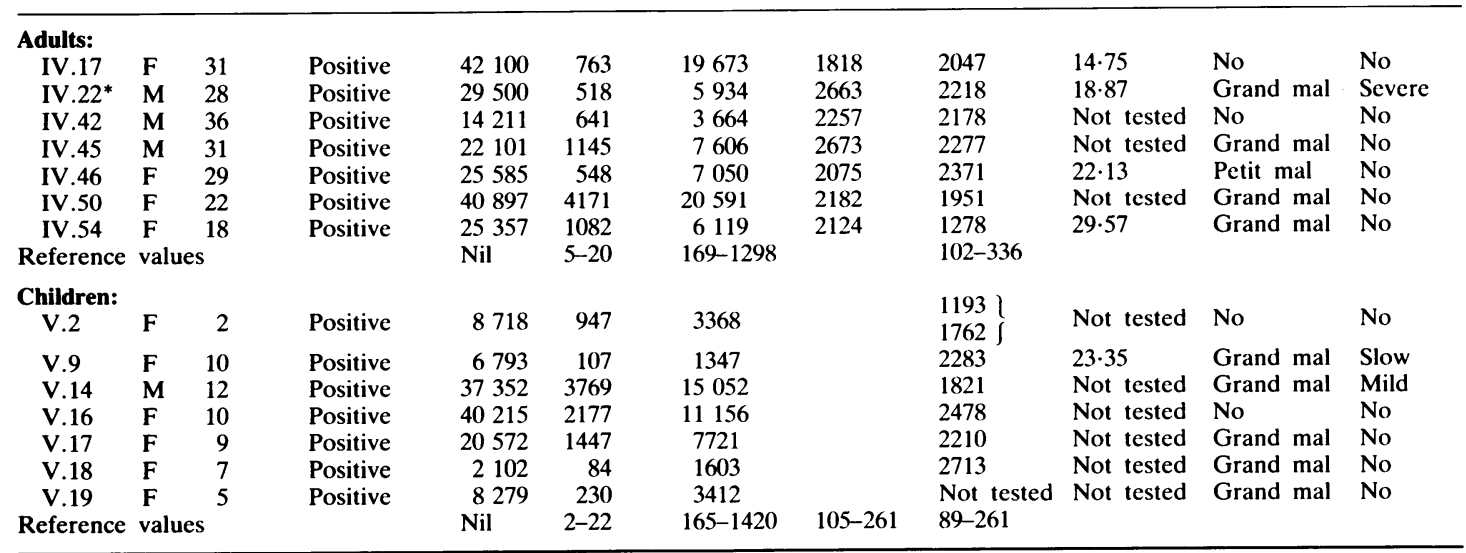

*Proband.

Samples of urine were random. 
Fifty other subjects ( 27 males, 23 females) had a serum proline concentration higher than the reference values. These are classified as having mild hyperprolinaemia. None of the 50 was found to have prolinuria. The proline concentration in seven was over $700 \mu \mathrm{mol} / \mathrm{l}$, being above the venous plasma concentration of $0.8 \mathrm{mM}(695 \mu \mathrm{mol} / \mathrm{l})$ at which prolinuria occurs according to Scriver et al. ${ }^{2}$ Quantitative urinalysis on one girl (V.28) with a serum concentration of $1278 \mu \mathrm{mol} / \mathrm{l}$ (confirmed on repeat test) showed no aminoaciduria. This girl and 16 others with mild hyperprolinaemia had normal concentrations of plasma P5C and had P5CD present in their peripheral leucocytes. The serum concentration in the 147 subjects tested is given in table 2 . With a single exception proline was the only raised serum amino acid. A mentally handicapped boy (V.34), with multiple congenital defects, had mild hyperprolinaemia $(546 \mu \mathrm{mol} / \mathrm{l})$ and mild alaninaemia $(555 \mu \mathrm{mol} / \mathrm{l})$. There was no apparent difference between fasting and non-fasting serum proline concentrations.

It proved convenient to test urine from nine of the 14 with prolinuria for orthoaminobenzaldehyde reactive substances. The findings ranged from 0.053 to 1.677 mean optical density value. Urine from 20 control (general hospital) patients gave a mean optical density value of 0.01325 with a range 0.00 to $0 \cdot 027$.

Tests for P5CD in peripheral leucocytes showed that it was undetectable in the five subjects with hyperprolinaemia and prolinuria who were tested. Their plasma P5C concentrations were high at $14 \cdot 75 ; 18 \cdot 87 ; 22 \cdot 13 ; 23 \cdot 35$, and $29.57 \mu \mathrm{mol} / \mathrm{l}$. The range in 32 pedigree members with normal plasma proline or mild hyperprolinaemia was $0 \cdot 128$ to 1.71 $\mu \mathrm{mol} / \mathrm{l}$. Two non-pedigree controls had concentra-

Table 2 Serum proline concentrations in the 147 members of the pedigree tested

\begin{tabular}{cc|cc}
\hline $\begin{array}{l}\text { Proline } \\
(\mu \mathrm{mol} / \mathrm{l})\end{array}$ & $\begin{array}{l}\text { No of } \\
\text { subjects }\end{array}$ & $\begin{array}{l}\text { Proline } \\
(\mu \mathrm{mol} / \mathrm{l})\end{array}$ & $\begin{array}{l}\text { No of } \\
\text { subjects }\end{array}$ \\
\hline $0-100$ & 1 & $1700-1800$ & $1^{*}$ \\
$>100-200$ & 26 & $>1800-1900$ & $1^{*}$ \\
$>200-300$ & 48 & $>1900-2000$ & 0 \\
$>300-400$ & 26 & $>2000-2100$ & $2^{*}$ \\
$>400-500$ & 14 & $>2200-2300$ & $2^{*}$ \\
$>500-600$ & 8 & $>2300-2400$ & $1^{*}$ \\
$>600-700$ & 4 & $2500-2600$ & $2^{*}$ \\
$>700-800$ & 5 & $2700-2800$ & $1^{*}$ \\
$>800-900$ & 1 & & \\
$1200-1300$ & 1 & Subtotal & 13 \\
\hline
\end{tabular}

*Indicates prolinuria. tions of 1.41 and $1.2 \mu \mathrm{mol} / \mathrm{l}$, respectively. All these 34 subjects showed the presence of P5CD in their peripheral leucocytes ranging from $6.83 \mathrm{nmol} / \mathrm{hour} /$ $\mathrm{mg}$ to $52.4 \mathrm{nmol} / \mathrm{hour} / \mathrm{mg}$. Summaries of the numbers tested, results, and findings relating to seizures and mental handicap are given in fig 3 . No significant association was shown between mental handicap and proline status. There was, however, a highly significant association between the occurrence of seizures and proline status when analysed by the $\chi^{2}$ test: $78 \cdot 39, p<0 \cdot 01$. The excess of seizures in those with raised proline was accounted for entirely by the group with type II hyperprolinaemia. There was no association between mild hyperprolinaemia and seizures.

With the object of establishing a contrast with the pedigree of the proband, the homes and caravans of all other non-pedigree travellers located in the same general area, to a total of 41 families with 259 children and young adults, were visited and medical histories taken. First cousin marriage was less common than in the proband pedigree. While not near related to the pedigree, some would have common ancestors. There were three $(1 \cdot 2 \%)$ with a history of recurrent seizures and none had an isolated single seizure. The pedigree families and the non-pedigree families were not matched for age and sex but were of generally similar structure. Just three of the non-pedigree travellers had serum proline estimated, all being normal.

FAMILY PEDIGREES AND CLINICAL FINDINGS

Among the pedigree sampled there were 71 marriages. Only three of these were not between first to third degree cousins. Families containing one or more members with hyperprolinaemia or other significant finding are set out in fig 2. Family members are numbered sequentially in birth order by generation. Because of the large size of completed families and widespread marriage of teenage first cousins only key family units of the pedigree are depicted.

The proband, who suffered from severe mental handicap and recurrent seizures, was one of 11 surviving children of 15 born live to a consanguineous union (family of III.2 and III.12). The father (III.2) had mild hyperprolinaemia. Five of the 20 pregnancies of the mother (III.12) ended in miscarriage and there were four deaths in infancy or childhood. Of the 11 survivors, five had severe mental handicap and physical defects. Of these five one, the proband, had appreciable hyperprolinaemia and two had mild hyperprolinaemia; these three were also subject to seizures, as were two who died in childhood. Of the six other 


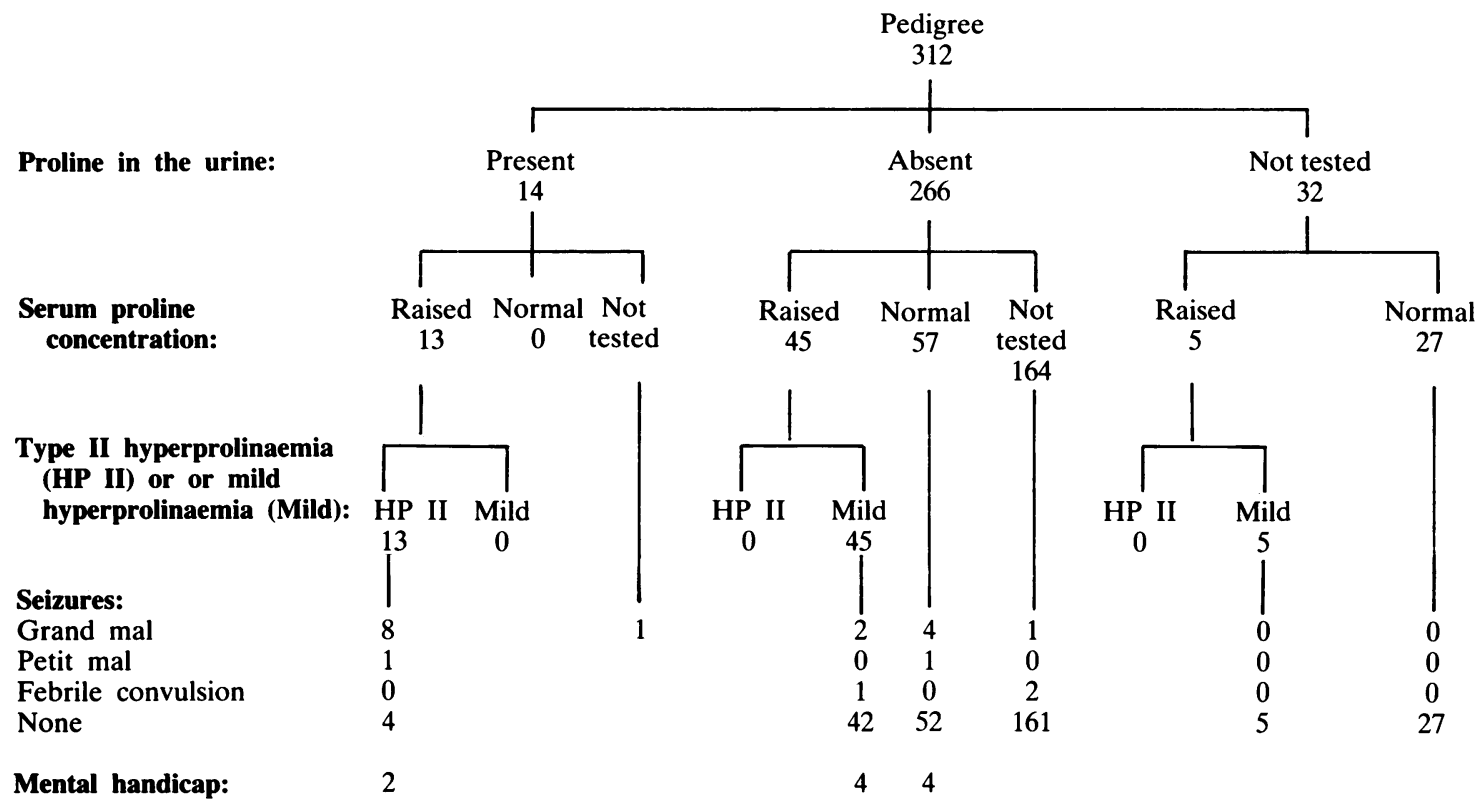

Fig 3 Presence of proline in urine and serum proline concentrations in members of the pedigree, showing the numbers having seizures and mental handicap.

survivors, five were generally healthy, one of whom (IV.17) had type II hyperprolinaemia and three had mild hyperprolinaemia (IV.13, 20, 24). Subject IV.17 suffered from occasional episodes of depression requiring hospitalisation but had no history of seizures. Six of her eight children had mild hyperprolinaemia but none had aminoaciduria (a newborn infant was not tested). The high morbidity and mortality in the offspring of III.2 and III.12 is exceptional for travellers.

The second most significant family of the pedigree was the 17 live born and surviving offspring of subject III.11 who was dead at the time of the survey, and of III.3 who declined sampling. This family were double first cousins of the proband's family. None had mental handicap. Five had type II hyperprolinaemia (IV.42, 45, 46, 50, and 54), four of whom gave a history of seizures in childhood. One of these (IV.45) had 10 children, five of whom had type II hyperprolinaemia, four with a history of recurrent seizures and one with mild mental handicap. Subject IV.41 with normal serum proline, had one child (V.9) with type II hyperprolinaemia, who had recurrent seizures and was a slow learner. Another member of the family (IV.43) had one child (V.28) who had mild hyperprolinaemia to a level of $1278 \mu \mathrm{mol} / \mathrm{l}$, normal urine, normal plasma P5C and P5CD present in peripheral leucocytes. This child had had a single childhood febrile convulsion and was a slow learner. Two other members of the family of III.11 and III.3, who had normal proline profiles, had had recurrent seizures which ceased in IV.44 at 22 years of age and was controlled in the other (IV.56) who was in his early teens. One of the four children of IV.48 had two febrile convulsions. The child's urine was normal. Plasma proline was not estimated. The children of IV.48 are not shown in fig 2 .

One other consanguineous couple had two children (V.40 and 41) with severe mental handicap and epilepsy since early childhood. Both had a normal urine and serum amino acid profile. The elder child died at 9 years of age subsequent to being studied. A third recently born child appeared normal. Their mother (IV.75) had mild hyperprolinaemia. One young woman (IV.38) developed grand mal seizures in late teenage. The second generation ancestor (II.2) suffered from traumatic epilepsy for five years before his death at 54 years of age.

In the remainder of the extended pedigree (not shown in fig 2) there was one child with spina bifida 
who had occasional seizures, two who had single febrile convulsions, and one with multiple congenital defects. Other than subject II.2, all the persons referred to are the offspring of teenage marriages of first cousins.

In addition to those of the proband, hospital records or discharge reports were available for eight of those with type II hyperprolinaemia in respect of 30 admissions because of seizures and fever ranging up to $41^{\circ} \mathrm{C}$. Upper respiratory tract infection, sometimes associated with vomiting, was the most common positive finding, with no evidence of major underlying pathology. There were three episodes of diarrhoea and meningism with negative results on lumbar puncture. Electroencephalographic reports were available for four pedigree children. Three with type II hyperprolinaemia gave a normal reading, but subject IV.56, with a normal proline profile and who was on maintenance anticonvulsants, indicated a convulsive tendency.

\section{MATERNAL HYPERPROLINAEMIA}

Four women with type II hyperprolinaemia had teenage marriages. Subject IV.17 had eight children, IV.46 had five children, IV.50 had three children, and IV.54 had two children. With a single exception, the children were physically and developmentally normal. The exception was the third child of IV.17. He was the child with mild hyperprolinaemia, alaninaemia, and multiple congenital defects referred to earlier (V.34). The mother of this family (IV.17), who suffered occasionally from depression, had a pulmonary embolus six days after her sixth confinement. A further confinement three years later was uneventful but her eighth confinement, after another six years, was followed by pulmonary embolus 10 days after the birth. Thus 17 of 18 children born to mothers with type II hyperprolinaemia appeared physically and developmentally normal. Five of the 10 children of one man with type II hyperprolinaemia (IV.45) had type II hyperprolinaemia, four had had seizures and one had mild mental handicap. The remaining five children were apparently healthy. Another man with type II hyperprolinaemia (IV.42) had eight healthy children (not shown in fig 2).

\section{Discussion}

The biochemical findings in 14 members of this pedigree fulfilled the established criteria for type II hyperprolinaemia, namely, appreciable hyperprolinaemia, iminoglycinuria, and orthoaminobenzaldehyde reactive substances in the urine. Unfortunately, it was not feasible to assay for leucocyte P5CD activity and plasma P5C in the entire pedigree because of the nomadic life style of some and unwillingness for further sampling in others. But in five affected and 31 other members of the pedigree in which P5CD and P5C assays were done, the initial diagnosis was confirmed in every case. In agreement with findings in previously reported pedigrees, proline was the sole raised serum amino acid. The unusual, if not unique, association of hyperglycinaemia with hyperprolinaemia reported by Pavone et al was not found in this series. ${ }^{11}$

An unexpected finding in this pedigree is the high number of subjects with mild hyperprolinaemia (approximately one third) for which we have no simple explanation. For type II hyperprolinaemia, Scriver et al outlined a straightforward association between phenotype and presumed genotype in this metabolic disorder with autosomal recessive inheritance. ${ }^{1}$ Probands and siblings with hyperprolinaemia exceeding $1300 \mu \mathrm{mol} / 1$ are homozygotes. Heterozygotes with intermediate activities of P5CD have normal serum proline concentrations. In the current pedigree the transmission of type II hyperprolinaemia, as represented by the 14 presumed homozygotes, is clearly autosomal recessive. Furthermore, the finding of normal plasma proline concentrations in eight children of one man with type II hyperprolinaemia (IV.42), all expected heterozygotes at the P5CD locus, is consistent with the idea that heterozygotes have decreased P5CD activities but do not have abnormalities in plasma proline. At first sight, the finding of mild hyperprolinaemia in six out of seven children tested from a union between a mildly hyperprolinaemic man (IV.71) and a woman with type II hyperprolinaemia (IV.17) may suggest a causal link between P5CD deficiency and mild hyperprolinaemia. Mild hyperprolinaemia occurred in the face of normal leucocyte P5CD activities, however, and normal concentrations of plasma P5C. Taken together, these findings suggest that mild hyperprolinaemia and P5CD deficiency are not associated. The physiological or biochemical basis for mild hyperprolinaemia remains unelucidated.

It is in the larger context of the association, if any, of clinical pathology to the metabolic abnormalities in hyperprolinaemia that this pedigree is of special interest. Only one of the seven previously reported probands was identified by screening. In all the others type II hyperprolinaemia was found by diagnostic studies for a clinical disorder-for example, seizures. Thus an association between clinical symptoms and hyperprolinaemia could not be made because of biased ascertainment. Moreover, the identification of asymptomatic siblings with type II hyperprolinaemia in certain pedigrees argues 
against a direct link to clinical symptoms. Consequently, most investigators consider type II hyperprolinaemia a benign disorder. ${ }^{1} 91112$

In the present series, diagnostic studies in pursuit of a causative factor for physical and mental disability applied only to the proband. The other 13 subjects with type II hyperprolinaemia were discovered during the survey of the proband's extended family. Six of the seven adults among the 14 cases of type II hyperprolinaemia are physically healthy and pursued a normal life. The seventh adult was severely handicapped mentally and suffered from recurrent seizures. Furthermore, fertility and fetal development were apparently normal as 18 children were born to four women with type II hyperprolinaemia. The one child with congenital defects and also the adult with severe mental handicap probably were chance occurrences. Thus findings in this pedigree generally support the prevalent belief that type II hyperprolinaemia is a benign condition. 19 11 12

Nevertheless, there is a striking association between type II hyperprolinaemia and childhood seizures, at least in this pedigree. Four of the seven adults had recurrent seizures in childhood. Five of the seven children had a history of recurrent seizures, often associated with fever, up to the age of 7 years. The severity of these episodes was attested by the necessity for their hospitalisation and treatment with anticonvulsants. Importantly, there is no association of mild hyperprolinaemia and seizures.

It could be argued that the observed association of seizures with type II hyperprolinaemia in this pedigree was related to the unusual lifestyle of the traveller population. Thus we surveyed a population to serve as controls. With few exceptions, all travellers available within the catchment area were surveyed to minimise selection bias. There were 24 persons $(4.2 \%)$ with a history of seizures among the 571 pedigree and non-pedigree travellers studied. This percentage is similar to that reported by Annegers et al from Rochester, Minnesota, where the incidence of any type of seizure through age 20 years was $4.1 \% .{ }^{22}$ When the occurrence of seizures in the pedigree travellers is compared with that in the non-pedigree travellers a significant difference is shown $\left(\chi^{2}=9.58, \mathrm{p}<0.01\right)$. In the pedigree group, 16 of 21 with seizures were among the 64 with raised serum proline or prolinuria and the excess over the expected in those with raised proline is accounted for entirely by the group with type II hyperprolinaemia (fig 3 ).

What remains, therefore, is the explanation for this documented association of seizures with type II hyperprolinaemia in this pedigree. One possible explanation is that linkage occurs at the genetic rather than at the enzymatic level-that is, the predisposition to seizures is unrelated to the metabolic consequences of absent P5CD activity. Instead, some other gene responsible for the inherited tendency to seizures may be closely linked to the gene for P5CD. Although there is no evidence supporting this hypothetical linkage, it cannot be ruled out.

A much more likely explanation is that the predisposition to seizures is a consequence of the metabolic derangement caused by the absence of P5CD activity. Several of these derangements have been shown by direct measurement in type II hyperprolinaemia including raised plasma and, presumably, cellular concentrations of proline and pyrroline-5-carboxalate. Certainly, proline itself has been found to be a neuromodulator, ${ }^{6}$ and specific high affinity uptake mechanisms for proline regulated by neuropeptides have been characterised in brain synaptosomes. ${ }^{23}$

In addition, pyrroline-5-carboxylate, a constituent of normal plasma, ${ }^{19}$ is a potent effector in transferring reducing-oxidising potential into cells. ${ }^{24} 25$ Its uptake is mediated by a specific carrier mechanism that transfers oxidising potential pari passu cell entry. ${ }^{26}$ Due to this transfer of oxidising potential, P5C appreciably effects glucose metabolism by stimulating the activity of the pentose phosphate shunt. ${ }^{24-26}$ Importantly, cultured human glioma cells are very sensitive to this effect of P5C. ${ }^{27}$ It is tempting to speculate that these effects of proline and P5C, which have been shown in vitro, are related to the predisposition to seizures. In the case of P5C, its perturbation of glucose metabolism if superimposed on hypoglycaemic and febrile episodes, both common occurrences in childhood, may be especially relevant in the association of seizures with type II hyperprolinaemia.

We are grateful to Dr Charles R Scriver for helpful comments and suggestions and for carrying specimens from Dublin to Bethesda, Maryland, USA. ${ }^{1}$ We thank Mr Thomas F McCormack, chief technologist, General Hospital, Mullingar for carrying out the tests for urinary orthoaminobenzaldehyde-reactive substances. The proband was discovered by Dr PF Deasy, paediatrician. We are especially grateful to the subjects of the study who, in general, readily responded to the approaches of one of us (MPF) for participation and sampling, without a clear understanding of the reasons for the requests. We wish to thank the many public health, clinic, and hospital nurses, doctors, and social workers who assisted with the collection of some urine and blood samples. Clinical information was kindly made available by Drs CD Quinlan, F McKenna, TW Waldron, JV Halpenny, J Clinch, E O'Connor, and Professor DG Gill. Testing for IQ was generously performed by Liz Brosnan. We thank the Midland Health Board for facilities. 


\section{References}

1 Scriver CR, Smith RJ, Phang JM. Disorders of proline and hydroxyproline metabolism. In: Stanbury JB, Wyngaarden JB, Fredickson DS, Goldstein JL, Brown MS, eds. The metabolic basis of inherited diseases. 5th ed. New York: McGraw-Hill, 1983.

2 Scriver CR, Efron ML, Schafer IA. Renal tubular transport of proline, hydroxyproline and glycine in health and in familial hyperprolinemia. J Clin Invest 1964;43:374-85.

3 Whelan DT, Connor WT. Maternal hyperprolinaemia. Lancet 1980;ii:981.

4 Adams E, Frank A. Metabolism of prolines and the hydroxyprolines. Annu Rev Biochem 1980;49:1005-61.

5 Schafer IA, Scriver CR, Efron ML. Familial hyperprolinemia, cerebral dysfunction and renal anomalies occurring in a family with hereditary nephropathy and deafness. $N$ Engl $J$ Med 1962;267:51-60.

${ }^{6}$ Felix D, Kunzle H. Iontophoretic and autoradiographic studies on the role of proline in nervous transmission. Pflugers Arch 1974;350:135-44.

7 Perry TL, Hardwick DF, Lowry RB, Hanson S. Hyperprolinaemia in two successive generations of a North American family. Ann Hum Genet 1968;31:401-7.

${ }^{8}$ Simila S, Visakorpi JK. Hyperprolinaemia without renal disease. Acta Paediatr Scand [Suppl] 1967;177:122.

${ }^{9}$ Mollica F, Pavone L, Antener I. Pure familial hyperprolinemia: isolated inborn error of aminoacid metabolism without other anomalies in a Sicilian family. Pediatrics 1971;48:225-31.

10 Sardharwalla IB, Hill A. Infantile hyperprolinaemia. Arch Dis Child 1975;50:745.

" Pavone L, Mollica F, Levy HL. Asymptomatic type II hyperprolinaemia associated with hyperglycinaemia in three sibs. Arch Dis Child 1975;50:637-41.

12 Mollica F, Pavone L. Hyperprolinaemia: a disease which does not need treatment? Acta Paediatr Scand 1976;65:206-8.

13 Flynn MP. Mortality, morbidity and marital features of travellers in the Irish midlands. Ir Med $J$ 1986;79:308-10.

14 Anonymous. Report of the Travelling People Review Body. Dublin: The Stationery Office, 1983.

15 Thomas JD. Gypsies and American medical care. Ann Intern Med 1985;102:842-5.

${ }^{16}$ Dickenson JC, Rosenblum H, Hamilton PB. Ion exchange chromatography of the free aminoacids in the plasma of the newborn infant. Pediatrics 1965;36:2-13.

17 Clayton BE, Jenkins P, Round JM. Paediatric chemical pathology: clinical tests and reference ranges. Oxford: Blackwell Scientific Publications, 1980.

${ }^{18}$ Strecker JD. The interconversion of glutamic acid and proline. The formation of $\triangle$-pyrroline-5-carboxylic acid from glutamic acid in Escherichia coli. J Biol Chem 1957;225:825-34.

${ }^{19}$ Fleming GA, Hagedon CH, Granger AS, Phang JM. Pyrroline5-carboxylate in human plasma. Metabolism 1984;33:739-42.

${ }^{20}$ Valle D, Goodman SI, Applegart DA, Shih VE, Phang JM. $\triangle$-pyrroline-5-carboxylic acid dehydrogenase deficiency in cultured skin fibroblasts and circulating lymphocytes: $J$ Clin Invest 1976;58:598-603.

${ }^{21}$ Lowry OH, Rosbrough NJ, Farr AL, Randall RJ. Protein measurement with the folin phenol reagent. J Biol Chem 1951;193:265-75.

22 Annegers JF, Hauser WA, Anderson VE, Kurlund LT. The risks of seizure disorders among relatives of patients with childhood onset epilepsy. Neurology 1982;32:174-9.

${ }^{23}$ Rhoads DE, Samkaram H, Raghupathy E. Selective inhibition of synaptosomal proline uptake by leucine and methionine enkephalins. J Biol Chem 1983;258:12233-7.

24 Phang JM, Downing SJ, Yeh GC, Smith RJ, Williams JA. Stimulation of the hexose-monophosphate pentose pathway by $\triangle^{\prime}$-pyrroline-5-carboxylate in cultured cells. J Cell Physiol 1982;110:255-61.

25 Yeh GC, Phang JM. Stimulation of phosphoribosyl pyrophosphate and purine nucleotide production by pyrroline-5carboxylate in human erythrocytes. $J$ Biol Chem 1988;263:13083-9.

${ }^{26}$ Mixson AJ, Phang JM. The uptake of pyrroline-5-carboxylate: group translocation mediating the transfer of reducing-oxidising potential. J Biol Chem 1988;263:10720-4.

27 Loreck DJ, Galarraga J, Van der Feen J, Phang JM, Smith BH, Cummins CJ. Regulation of the pentose phosphate pathway in human astrocytes and gliomas. Metabolic Brain Disease 1987;2:31-46.

Correspondence and requests for reprints to Dr MP Flynn, 1 Ballinderry, Mullingar, Republic of Ireland.

Accepted 31 March 1989 